\title{
Indole-3-acetic Acid Catabolism by Soybean Bacteroids
}

\author{
By J. RIGAUD AND A. PUPPO \\ Faculté des Sciences, Laboratoire de Biologie végétale, Parc Valrose, \\ o6034 Nice Cedex, France
}

(Received I9 June I974; revised I I October 1974)

\begin{abstract}
SUMMARY
Bacteroid preparations from nodules of soybean were able to destroy aerobically substantial quantities of indole-3-acetic acid (IAA). Kinetic studies indicate the involvement of two processes. The supernatant derived during preparation of bacteroids had an active IAA oxidation during the first $30 \mathrm{~min}$. Successive washings of bacteroids still retained some activity although it was reduced. A high level of IAA destruction was always observed with washed bacteriods and the reaction proceeded linearly for at least $4 \mathrm{~h}$. Glucose gave a slight stimulation but succinate, pyruvate and fumarate at low concentrations (approx. $25 \mathrm{~mm}$ ) were strong inhibitors. No IAA catabolism occurred with washed bacteroids at a $\mathrm{PO}_{2}$ of $30 \mathrm{mmHg}$ or less, but it increasingly occurred with further increase in oxygen partial pressure up to $150 \mathrm{mmHg}$. No difference was observed between bacteroids with or without active nitrogenase.
\end{abstract}

\section{INTRODUCTION}

Significant quantities of indole-3-acetic acid (IAA) occur in the nodules of different legumes (Pate, I958; Dullaart, I967). Mennes (I972) reported IAA degradation in nodules of Lupinus and suggested that bacteroids were not involved in this activity. Earlier results showed that different strains of free living Rhizobium could destroy IAA (Rigaud, I969; Dullaart, 1970) and it was of interest to investigate the possible role of bacteroids in this catabolism. We report an IAA-oxidase activity in preparations of soybean bacteroids; the effects of substrates and oxygen tensions were also investigated.

\section{METHODS}

Nodules. Soybeans (Glycine max Merr., cultivar Altona) inoculated with Rhizobium japonicum CC705 (syn. Wisconsin 505), were grown in a glasshouse (temperature range 20 to $27^{\circ} \mathrm{C}$ ) in plastic pots in a $2: \mathrm{I}$ mixture of washed vermiculite and sand. The composition (g/l) of the culture medium was: $\mathrm{KH}_{2} \mathrm{PO}_{4}, 0 \cdot 2 ; \mathrm{MgSO}_{4} \cdot 7 \mathrm{H}_{2} \mathrm{O}, 0 \cdot 2 ; \mathrm{KCl}, 0 \cdot 2 ; \mathrm{CaSO}_{4} \cdot 2 \mathrm{H}_{2} \mathrm{O}$, $0.12 ; \mathrm{Na}_{2}$ FeEDTA, $0.025 ; \mathrm{Na}_{2} \mathrm{MoO}_{4} .2 \mathrm{H}_{2} \mathrm{O}, 0.004$; and microelements as recommended by Heller (I953). Nodules were harvested about 40 days after sowing (nodule age $3 \mathrm{I}$ to 32 days).

Bacteroid suspensions. Nodules (about $\mathrm{I} 5$ to $35 \mathrm{~g}$ fresh wt) were crushed aerobically in Bergersen \& Turner's (I970) mixture, except that sodium ascorbate was omitted. The bacteroid preparations with active nitrogenase were prepared anaerobically under argon with a modified Sorvall Omni-mixer according to Bergersen \& Turner (I973). After filtration of the homogenate, a first centrifugation $(300 \mathrm{~g})$ removed plant cell debris. Bacteroids were separated by a second centrifugation $(6800 \mathrm{~g})$, washed twice with a phosphate buffer 


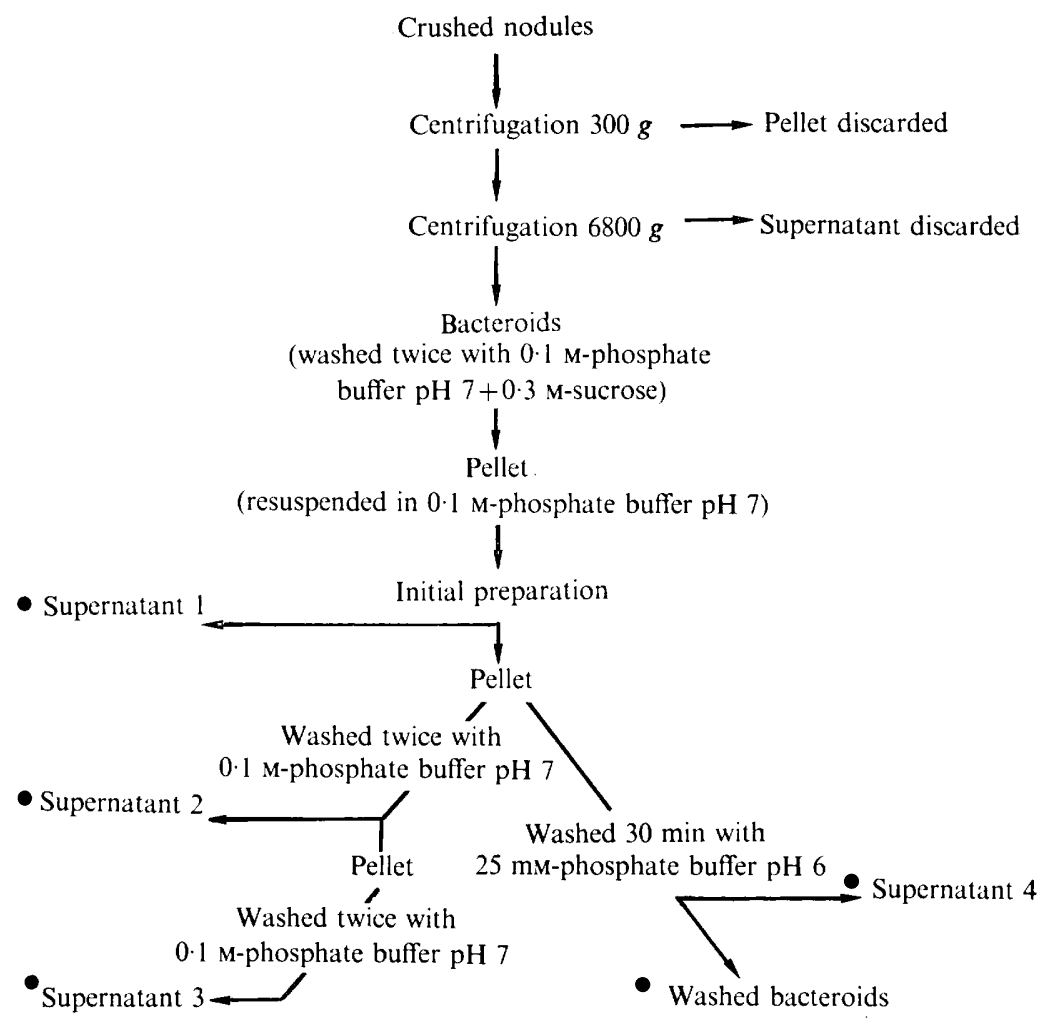

Fig. I. General scheme for the preparation of soybean bacteroids. Oxidation of IAA was tested at different steps $(\mathbf{O})$.

$(\mathrm{O} \cdot \mathrm{I} \mathrm{M}, \mathrm{pH} 7)$ containing sucrose $(0.3 \mathrm{M})$, and resuspended in phosphate buffer. This method was regarded as the initial preparation of bacteroids.

In addition, these bacteroids were sometimes washed with citrate-phosphate buffer (O. I M) or phosphate buffer ( 25 to I00 $\mathrm{mm}$ ) at several $\mathrm{pH}$ values. Figure I gives a general scheme for the preparation of bacteroids and shows the successive steps when the degradation of IAA was tested.

IAA-oxidase activity. Glass vials $(25 \mathrm{ml})$ were used, containing IAA $(0.3 \mathrm{~mm})$ in $2 \mathrm{ml}$ of phosphate buffer ( $25 \mathrm{mM}, \mathrm{pH} 6)$, sometimes with added substrates such as glucose, sodium succinate or sodium fumarate at various concentrations. Reactions in duplicate were initiated by the addition of bacteroids ( 20 to $30 \mathrm{mg}$ dry wt/assay) or a volume of supernatant derived from this quantity. The flasks, plugged with cotton wool, were agitated on a reciprocating shaker at $\mathrm{I} 00 \mathrm{rev} . / \mathrm{min}$ at $30^{\circ} \mathrm{C}$. To stop the reaction, $0 . \mathrm{I} \mathrm{ml}$ of $\mathrm{NaOH}$ ( I M) was added.

To obtain anaerobic conditions or low oxygen tensions, the vials were capped with rubber seals, evacuated, and filled with nitrogen or with nitrogen and oxygen at different partial pressures. The reactions were started by the injection of bacteroids.

The IAA concentrations were estimated colorimetrically (Pilet \& Collet, 1962).

Nitrogenase activity. The assays were carried out in $18 \mathrm{ml}$ Warburg vessels as described by Rigaud et al. (1973). The activity was measured by $\mathrm{C}_{2} \mathrm{H}_{2}$ reduction (Hardy et al. 1968) using a Pye Unicam gas chromatograph fitted with a column of Porapak R. 


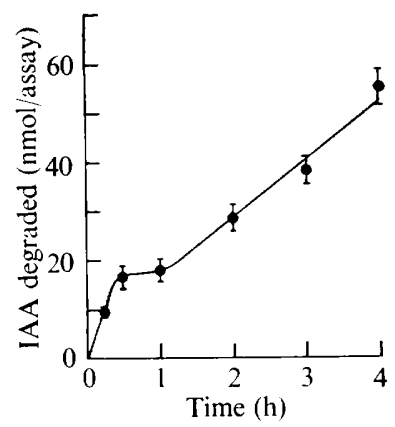

Fig. 2. Time course of IAA oxidation by initial preparations of bacteroids. Incubation mixtures $(2 \mathrm{ml})$ contained IAA $(0.3 \mathrm{~mm})$ and bacteroids $(20 \mathrm{mg}$ dry $\mathrm{wt})$ in a phosphate buffer $(\mathrm{O} . \mathrm{I} \mathrm{M}, \mathrm{pH} 7)$, and were shaken at $100 \mathrm{rev} / \mathrm{min}$ at $30^{\circ} \mathrm{C}$. Vertical bars represent $\pm \mathrm{I}$ standard deviation.
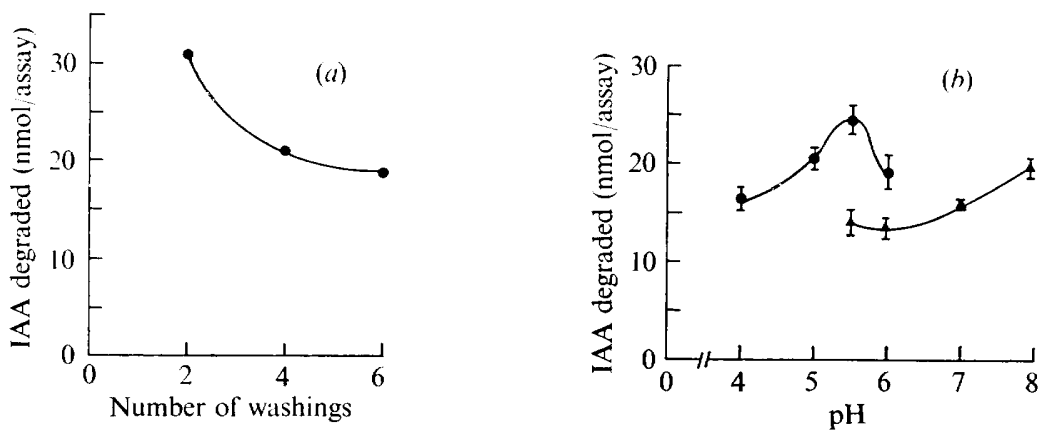

Fig. 3. Effect of $(a)$ the number of washings, and $(b)$ the nature and pH of buffers, upon IAA degradation by the supernatants. After initial preparation, bacteroids were washed for $3 \mathrm{~min}$ (a) 2, 4 or 6 times with phosphate buffer $\mathrm{pH} 7(100 \mathrm{mM})$, or $(b)$ twice with $(\Delta)$ phosphate buffer ( $100 \mathrm{~mm}$ ), or $(0)$ citrate-phosphate buffer (I00 mM). Incubation mixtures $(2 \mathrm{ml})$ contained IAA $(0.3 \mathrm{~mm})$ and supernatant derived from $22 \mathrm{mg}$ dry wt of bacteroids, and were shaken at 100 $\mathrm{rev} . / \mathrm{min}$ for $30 \mathrm{~min}$. Vertical bars represent \pm 1 standard deviation.

\section{RESULTS}

\section{IAA degradation by initial preparations of bacteroids}

Active degradation of IAA ( $54 \mathrm{nmol} /$ assay) was obtained for $4 \mathrm{~h}$ without an energy substrate. The time course (Fig. 2) indicates three steps: a high initial rate, a short lag time, and a subsequent rate which is lower than the initial rate and remains constant for at least $3 \mathrm{~h}$.

\section{IAA-oxidase activity in the supernatants}

The supernatant I remaining after the initial preparation induced the disappearance of about $20 \mathrm{nmol}$ IAA in $2 \mathrm{~h}$. There was a decrease of IAA oxidation after successive washings with phosphate buffer (supernatant 2), although even after six washings substantial activity persisted in supernatant 3 (Fig. $3 a$ ). The influence of the buffer characteristics (constituents, $\mathrm{pH}$ and ionic strength) on the activity in these supernatants was investigated. Least IAA oxidation was obtained with $0.1 \mathrm{M}$-phosphate buffer, $\mathrm{pH} 5.5$ and 6 (Fig. 3 ). More activity was found at higher $\mathrm{pH}$ and with citrate-phosphate buffer $\mathrm{pH} 4$ to 6 . Phosphate concentration had little effect over the range 100 to $25 \mathrm{mM}$, at $\mathrm{pH}$, although least activity was obtained at $25 \mathrm{~mm}$. 

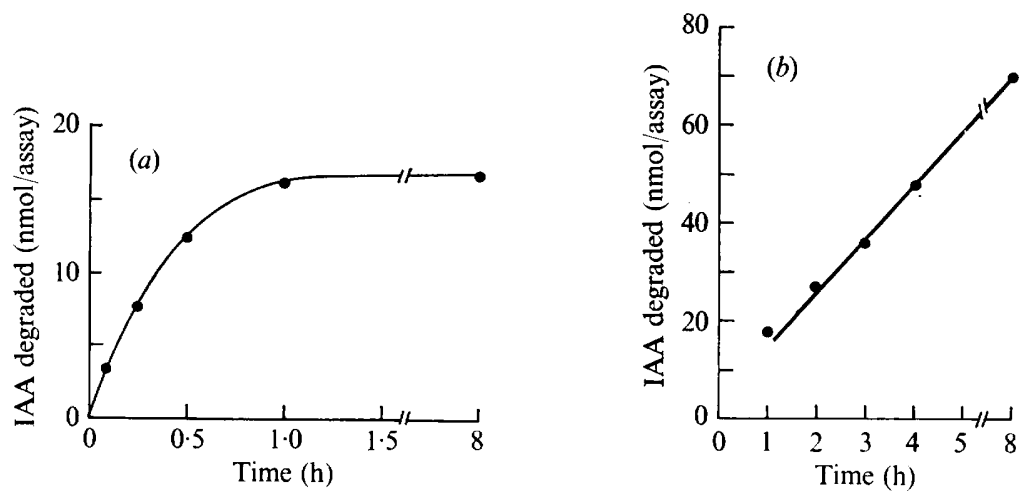

Fig. 4. Time course of IAA oxidation $(a)$ by supernatant 4 and $(b)$ by washed bacteroids. Incubation mixtures $(2 \mathrm{ml})$ contained IAA $(0.3 \mathrm{~mm})$ and $27 \mathrm{mg}$ dry wt of $(a)$ supernatant 4 or $(b)$ washed bacteroids in 25 mm-phosphate buffer $\mathrm{pH} 6$. The vessels were shaken at $30^{\circ} \mathrm{C}$.
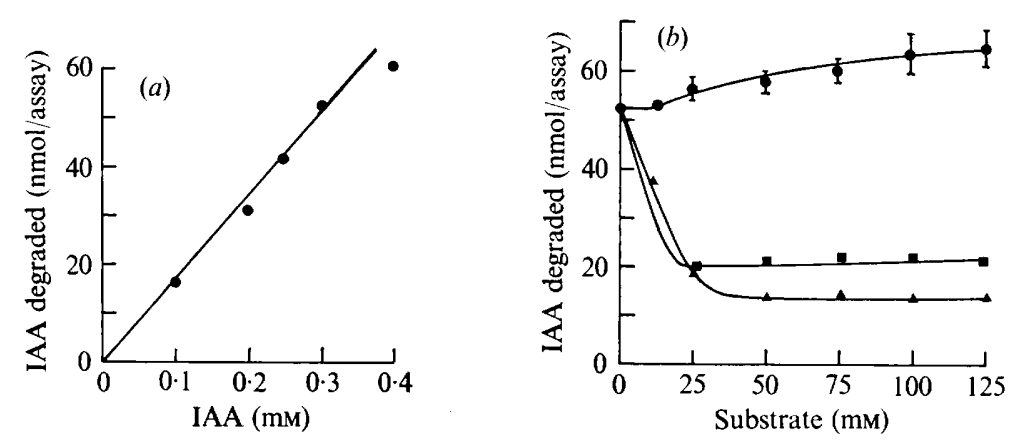

Fig. 5. The effect of the concentrations of $(a)$ IAA, and $(b)$ glucose, sodium succinate and sodium fumarate, upon IAA degradation by washed bacteroids. (a) Incubation mixtures ( $2 \mathrm{ml}$ ) contained IAA at different concentrations and bacteroids ( $30 \mathrm{mg}$ dry wt) in $25 \mathrm{~mm}$-phosphate buffer, $\mathrm{pH} 6$. (b) The bacteroids ( $24 \mathrm{mg}$ dry wt), resuspended in $25 \mathrm{~mm}$-phosphate buffer, $\mathrm{pH} 6$, were incubated, for a final volume of $2 \mathrm{ml}$, with $0.3 \mathrm{~mm}$-IAA plus $(\boldsymbol{\Delta})$ succinate, $(\boldsymbol{\square})$ fumarate, or $(\boldsymbol{O})$ glucose. Assayed at $30^{\circ} \mathrm{C}$ with shaking ( $100 \mathrm{rev} / \mathrm{min}$ ). Vertical bars represent $\pm \mathrm{I}$ standard deviation.

In later experiments, after the initial preparation, the bacteroids were washed by shaking (I00 rev./min) for $30 \mathrm{~min}$ at $30{ }^{\circ} \mathrm{C}$ in $25 \mathrm{~mm}$-phosphate buffer pH 6 . The time course of IAA oxidation by the supernatant 4 , in these conditions, is shown in Fig. 4(a). Degradation was rapid during the first $30 \mathrm{~min}$ but the rate declined after I h. No activity was observed during the following $7 \mathrm{~h}$.

\section{$I A A$ degradation by washed bacteroids}

IAA was destroyed by bacteroids at a linear rate for up to $4 \mathrm{~h}$ (Fig. $4 b$ ). To estimate the activity of bacteroids alone, the first value was determined after I $\mathrm{h}$. The reaction proceeded linearly for $4 \mathrm{~h}$, and for further experiments we used the value of IAA degraded between the 2nd and the 5 th hour.

The rate of IAA oxidation increased with increasing IAA concentration up to $0.35 \mathrm{mM}$ (Fig. 5a). For the following assays 0.3 mM-IAA was used.

The effects of different substrates upon IAA oxidation by washed bacteroids are shown in Fig. 5(b). A slight stimulation was observed with increasing concentrations of glucose 


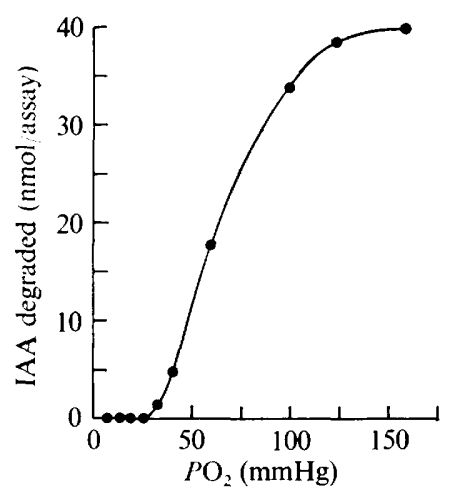

Fig. 6. Effect of oxygen partial pressures upon IAA degradation by washed bacteroids. The vessels contained $25 \mathrm{~mm}$-phosphate buffer, $\mathrm{pH}$ 6, plus IAA $(0 \cdot 3 \mathrm{~mm})$, washed bacteroids ( $20 \mathrm{mg}$ dry wt) and glucose $(50 \mathrm{~mm})$, and were shaken (100 rev. $/ \mathrm{min})$ at $30{ }^{\circ} \mathrm{C}$. The other gas present was argon.

$(20 \%)$; the optimal effect was reached with $100 \mathrm{~mm}$. Higher levels of glucose, as well as sucrose up to $300 \mathrm{~mm}$, did not substantially increase IAA degradation, suggesting that an osmotic effect was not involved. In contrast, relatively small concentrations of succinate or fumarate ( $25 \mathrm{mM}$ ) strongly inhibited IAA oxidation by washed bacteroids (Fig. $5 b$ ); pyruvate gave similar results.

Oxidation of IAA by washed bacteroids was oxygen-dependent. For low oxygen tensions, up to $40 \mathrm{mmHg}$, a little IAA destruction was observed (Fig. 6). Higher partial pressures sharply increased this activity, reaching a maximum at $120 \mathrm{mmHg}$.

In contrast with the preceding experiments with bacteroids prepared in aerobic conditions, we also used an anaerobic preparation procedure to prevent nitrogenase destruction. In both cases the results were similar in the range of $\mathrm{O}_{2}$ partial pressures up to $38 \mathrm{mmHg}$, which did not inactivate nitrogenase for this strain of bacteria (Rigaud et al. 1973). With $\mathrm{O}_{2}$ as terminal electron acceptor, succinate and fumarate have been reported to be efficient substrates supporting nitrogen fixation by these bacteroids (Bergersen \& Turner, 1967). In our experiments, because these compounds inhibited IAA-oxidase activity (Fig. $5 b$ ) we used glucose as substrate, despite its low efficiency for nitrogen fixation.

\section{DISCUSSION}

A substantial destruction of IAA is observed on incubation with soybean bacteroids. The time course of this reaction (Fig. 2) suggests that two different processes may be involved in this catabolism. The high initial rate observed during the first 30 min suggests an enzymic activity not directly dependent on the bacteroids themselves. This is supported by the ability of supernatants alone to destroy IAA strongly during the initial $30 \mathrm{~min}$, the reaction ending after $\mathrm{I} h$ (Fig. $4 a$ ). Successive washings of the bacteroids (Fig. 3a) reduced IAA oxidation activity, in agreement with the results of Mennes (1972), but more than $60 \%$ of the original activity was still present in the sixth washing solution. A relationship was observed between activity in the supernatants and the characteristics of the washing buffers. Possibly this activity derives from the plant organelles. In our experiments this seems unlikely because plant cell debris was removed by several steps of centrifugation (see Methods) and the bacteroids were washed several times. On the other hand, this activity could come 
from particles bound to the bacteroids as proposed by Mennes (1972), or from the bacteroids themselves by leakage .

A second phase of IAA oxidation in which bacteroids alone are involved was observed after I h. The existence of a similar lag phase was reported by Rigaud (1969) with free living Rhizobium and this might be due to the slow penetration of IAA into the bacteroids. Under our experimental conditions no relationship was observed between oxidation of IAA and nitrogenase activity. To prevent an inhibition of IAA oxidase, substrates which stimulate nitrogen fixation by bacteroids (succinate, fumarate or pyruvate) were omitted, and this certainly limited nitrogenase activity.

A low oxygen partial pressure reduced the oxidation of IAA by bacteroids. A similar oxygen requirement for IAA oxidase was reported by Rigaud (I969) with free living Rhizobium. The low oxygen tensions likely to occur in the nodules could limit the degradation of IAA by the bacteroids.

Mennes (1972) reported that lupin bacteroids are devoid of IAA-oxidase activity; the use of fresh nodules and the protection of IAA oxidase from non-specific binding with phenolic products during the preparation procedure, as suggested by Sequeira (I973), achieved here with polyvinylpyrrolidone could partly explain the lack of agreement with our results.

\section{REFERENCES}

Bergersen, F. J. \& Turner, G. L. (1967). Nitrogen fixation by the bacteroid fraction of breis of soybean root nodules. Biochimica et biophysica acta I4I, 507-5 I 5 .

Bergersen, F. J. \& Turner, G. L. (1970). Gel filtration of nitrogenase from soybean root nodule bacteroids. Biochimica et biophysica acta 214, 28-36.

Bergersen, F. J. \& Turner, G. L. (1973). Kinetic studies of nitrogenase from soybean root nodule bacteroids. Biochemical Journal $\mathbf{1 3}$ I, 6I-75.

DullaART, J. (1967). Quantitative estimation of indole acetic acid and indole carboxylic acid in root nodules and roots of Lupinus luteus L. Acta botanica neerlandica 16, 222-230.

DullaArT, J. (1970). The bioproduction of indole-3-acetic acid and related compounds in root nodules and roots of Lupinus luteus $\mathrm{L}$. and by its rhizobial symbiont. Acta botanica neerlandica 19, 573-618.

Hardy, R. W. F., Holsten, R. D., Jackson, E. K. \& Burns, R. C. (1968). The acetylene-ethylene assay for N-fixation: laboratory and field evaluation. Plant Physiology 43, II 85-I 207.

Heller, R. (1953). Recherches sur la nutrition minérale des tissus végétaux cultivés in vitro. Annales de Sciences naturelles, de Botanique et de Biologie Végétale, $\mathrm{I}-223$.

MENNES, A. M. (1972). Indole-3-acetic acid oxidase activity in root nodules and roots of Lupinus luteus L. Purification and kinetics of the enzyme. Thesis, University of Leiden.

PATE, J. S. (1958). Studies of the growth substances of legume nodules using paper chromatography. Australian Journal of Biological Sciences II, 516-528.

Pilet, P. E. \& Collet, G. (1962). Méthode d'Analyse du Catabolisme auxinique .Lausanne: Zwahlen.

Rigaud, J. (1969). Croissance, teneur en auxine et catabolisme auxinique chez Rhizobium. Archiv für Mikrobiologie 66, 29-33.

Rigaud, J., Bergersen, F. J., Turner, G. L. \& Daniel, R. M. (1973). Nitrate dependent anaerobic acetylene-reduction and nitrogen-fixation by soybean bacteroids. Journal of General Microbiology 77, $137-\mathrm{I} 44$.

SequeIra, L. (1973). Hormone metabolism in diseased plants. Annual Review of Plant Physiology 24, $353-380$. 